\title{
Gamma-delta Tocotrienol
}

National Cancer Institute

\section{Source}

National Cancer Institute. Gamma-delta Tocotrienol. NCI Thesaurus. Code C101517.

An orally available nutritional supplement containing the gamma and delta forms of the vitamin E family member tocotrienol, with hypocholesterolemic, antithrombotic, antioxidant, and potential antineoplastic activity. Upon oral administration, gamma-delta tocotrienol accumulates in cancer cells and may exert their anti-cancer activity in part through 3-hydroxy-3-methylglutaryl coenzyme A (HMG-CoA) reductase downregulation and/or degradation, cell cycle arrest, and induction of caspase-mediated apoptosis. In addition, this agent may inhibit angiogenesis partially through the blockage of vascular endothelial growth factor receptor (VEGFR) and the inhibition of tumor cell-induced vessel formation. Altogether, this may result in the inhibition of tumor cell growth. Further, this agent prevents free radical formation and inhibits lipid peroxidation. Tocotrienols contain 3 double bonds, absent in tocopherols, on its farnesyl isoprenoid side chain that likely contribute to its anti-cancer activities. 